$$
\begin{gathered}
\text { 이용자 중심의 스마트공원 조성을 위한 공원서비스의 } \\
\text { 상대적 중요도 분석 } \\
\text { 이주용 }{ }^{*} \text { 이형숙** }
\end{gathered}
$$

"경북대학교 대학원 조경학과 대학원생 · "경북대학교 조경학과 교수

\title{
An Analysis of the Relative Importance of Park Services for User-Oriented Smart Park Development
}

\author{
Lee, Ju-Yong ${ }^{*} \cdot$ Lee, Hyung-Sook* \\ "graduate student, Dept. of Landscape Architecture, Graduate School, Kyungpook National University \\ "Professor, Dept. of Landscape Architecture, Kyungpook National University
}

\begin{abstract}
Interest in smart parks has been increasing due to the recent rapid rise of smart cities, but concerns are growing over the development of technology-oriented smart parks. The purpose of this study is to evaluate the relative importance of park services through Focus Group Interviews and the Analytic Hierarchy Process (AHP) to develop user-oriented smart parks in the future. To this end, literature on park functions and services was reviewed, and interviews with experts in the field of landscape architecture and IT were conducted to derive service items. The AHP model consisted of four values, and 15 park services were established and used to survey 38 landscape experts. As a result, services for improving the park's essential functions, such as contact with nature, relaxation, and exercise-walking, were deemed important. Services related to the environment and safety in response to climate change, such as the amelioration of pollution and heatwaves were also high. The importance of social integration services was relatively low, but it was considered an important service to when enhancing community participation. Future smart parks should enhance the health benefits of contact with nature rather than implementing excessive artificial facilities and technology. Additionally, smart technology will need to be applied based on users' needs while reflecting local characteristics. Efforts should be made to enhance user intimacy and improve the understanding of smart parks by strengthening public relations education.
\end{abstract}

Keywords: Smart City, Smart Technology, Urban Park Value, Analytic Hierarchy Process

Corresponding author: Hyung-Sook Lee, Professor, Dept. of Landscape Architecture, Kyungpook National University, Daegu 41566, Korea, Tel.: +82-53-950-5781, E-mail: soolee@knu.ac.kr 


\section{국문초록}

최근 스마트도시의 급부상에 따라 스마트공원에 대한 관심이 증대되고 전국적으로 확산되고 있으나, 획일적인 시설물 도입과 기술 위주의 스마트공원 개발에 대한 우려 또한 커지고 있다. 본 연구는 향후 이용자 중심의 스마트공원을 개발하기 위해 지향해야 할 가치 및 우선적으로 고려될 공원서비스가 무엇일지 전문가와의 심층인터뷰와 계층분석기법을 통해 그 상대적 중요도를 평가하는 것을 목적으로 하였다. 이를 위해 공원 기능 및 서비스에 대한 선행연구 및 문헌을 고찰하였 고, IT전문가 및 조경분야 전문가를 대상으로 전문가 인터뷰를 2 차례 실시하여 내용분석을 통해 서비스 항목을 도출하였 다. 4 개의 가치와 15 개의 공원서비스로 구성된 $\mathrm{AHP}$ 모델을 구축하고 38 명의 조경 전문가들을 대상으로 한 설문조사를 통해 공원서비스의 중요도를 산정하였다. 그 결과, 자연접촉, 휴식, 운동 - 산책 등 공원의 본질적인 기능 향상을 위한 서비스의 중요도가 높았으며, 미세먼지나 폭염 등 기후변화에 대응하는 재난재해 방지 및 안전성 관련 서비스도 높게 나타났다. 사회통합 관련 서비스의 중요도 값은 상대적으로 낮았으나, 지역주민들의 참여와 체감도 제고에 있어서는 중요한 서비스로 논의되었다. 향후 스마트공원 개발에 있어 과다한 인공시설물과 기술의 도입으로 인해 자연접촉과 휴식이라는 기존의 공원 기능이 퇴색되지 않도록 하며, 이용자의 요구에 근거하고 지역특성을 반영하는 스마트기술의 적용이 필요할 것이다. 스마트공원의 홍보교육 강화를 통해 이용자의 친밀감을 높이고, 스마트공원에 대한 이해도를 제고하는 노력이 요구된다.

주제어: 스마트도시, 스마트 기술, 도시공원가치, 계층분석기법

\section{I. 서론}

급격한 도시화로 인한 각종 도시문제가 심화됨에 따라 도시 공간에 정보통신 융합기술과 친환경기술 등을 적용하여 행정, 교통, 방범방재, 에너지, 환경, 주거복지 등의 도시기능을 효율 화하고 도시문제를 해결하려는 스마트도시가 대두되고 있다 (Kim and Jung, 2019). 스마트도시의 개념은 초기 정보통신기 술을 통해 다양한 시설을 통합적으로 모니터링하여 도시자원 을 효율화하는 '도시기반시설 중심'의 관점으로 정의되었으나, 제 2 차 스마트도시 종합계획에서는 제도, 기능, 조직통합을 통 해 새로운 산업을 육성하기 위한 플랫폼(platform)으로 그 의 미가 확장되었으며(Kim and $\mathrm{Koo}, 2019)$, 최근 제3차 종합계획 에서는 도시 네트워크 구축, 체감형 서비스 실증, 산업생태계 조성 추진이라는 혁신체계의 개념으로 발전되었다(MOLIT, 2019). 이렇듯 스마트도시가 도시민들의 삶의 질을 높이고, 지 속적인 경제 - 환경 - 문화 전반의 도시발전을 이루는데 효과적 인 방안으로 대두됨에 따라 스마트공원에 대한 관심 또한 높아 지고 있다. 스마트공원은 사물인터넷(IoT), 빅데이터, 클라우드 컴퓨팅, 인공지능(AI), 무인자동차 및 드론 등의 첨단 ICT기술 이 공원에 융-복합되어 이용자, 시설- 환경이 상호 작용하는 공원으로 정의할 수 있다(Lee, 2018). 2017년 대구의 국채보상 운동기념공원의 스마트공원 시범사업을 시작으로 스마트시티 국가시범도시인 세종시와 부산시를 비롯하여 고양시, 시흥시에 새롭게 스마트공원이 계획되는 등 스마트공원이 전국적으로 확산되고 있다(Park, 2020).
기 조성된 스마트공원에는 $\mathrm{AR} \cdot \mathrm{VR}$ 서비스, 공공 $\mathrm{Wi}-\mathrm{Fi}$, 스 마트 공원 등, 서비스 안내 키오스크, 스마트 디지털 안내판, 태 양광 모바일 충전 벤치, 스마트 그림자조명, 인공지능 CCTV 등 ICT를 통해 원격제어하거나 센서를 통해 작동 시간과 작동 모드를 자율 판단하는 다양한 스마트 시설들이 도입되고 있다. 또한 토양, 기상, 수목의 상태 등을 모니터링하여 식재관리를 하는 스마트 파크케어 시스템, 미세먼지나 폭염대비를 위한 공 기정화시설 또는 쿨링 시스템 등 새로운 스마트 기술들이 공원 서비스에 접목되고 있다(Lee et al., 2019; Park, 2020).

이러한 스마트기술은 공원이용자의 안전과 편의를 향상시키 고, 공원관리 및 운영에 있어 효율성을 높이는 장점이 있지만, 현행 스마트공원 조성에 있어 여러 문제점도 지적되고 있다. U-City 사업과 관련하여 Yim et al.(2008)은 대부분의 스마트 사업 계획 및 실행이 수용능력과 기능의 고려없이 첨단기술이 도입되는 경우가 많아 한계점과 문제를 발생시킨다고 평가한 바 있는데, 이러한 비판이 스마트도시와 스마트공원 조성에 있 어서도 유효할 정도로 기술적 측면만이 강조되는 경향이 있다 (Kim and Ha, 2019; Kim et al., 2020). 스마트공원의 경우, 관 련 스마트 기술적용이 주로 벤치나 안내판 등의 단위 시설물 위주인 경우가 많으며, 공원의 운영 - 관리차원에서 전반적이고 체계적인 서비스 관점에서의 기술도입은 부족한 편이다. $\mathrm{Kim}$ et al.(2020)은 공원의 경관, 공간의 성격 및 맥락에 어울리지 않는 스마트기술의 시설물이 가시적 성과를 위해 도입됨에 따 라 이용률이 떨어지거나 방치되는 문제점을 지적하였다. 또한, 공원 이용자의 다양한 요구, 인식, 이용행태 분석에 근거하지 
않아 시민들의 인식 및 체감도가 낮을 뿐만 아니라, 유지관리 의 문제로 인한 실효성과 지속적인 활용에 대한 우려도 제기되 고 있다(Kim, 2017; Lee et al., 2019).

활발한 스마트도시 개발에 발맞추어 사회경제적 변화를 인 식하고, 미래지향적 대응을 위해 다양한 4차 산업혁명 기술의 적극적 도입은 필요하지만(Choi and Suh, 2019), 스마트 사업 의 핵심서비스가 수요자의 관점이 아닌 기술 위주로 계획되면 비효율적이고 비경제적인 개발이 될 우려가 있다(Jeong et al., 2009). 또한, 공원녹지의 전통적인 역할과 기능을 고려하였을 때 공원에 인공적인 첨단기술 도입에 대해서는 보다 신중한 접 근이 요구되며, 스마트기술의 전시장이 아닌 이용자 중심의 스 마트공원 조성을 위해서는 스마트공원이 지향해야 할 가치와 방향성, 우선적으로 제공되어야 할 공원서비스에 대한 활발한 논의와 연구가 필요할 것이다.

이에 본 연구는 향후 스마트공원 개발에 있어 지향해야 할 우선가치 및 목표가 무엇이며, 이를 위해 우선적으로 제공되어 야 하는 공원서비스가 무엇일지에 대한 연구문제를 설정하였 다. 이를 위해 조경분야와 IT기술 전문가와의 심층 인터뷰와 계층분석기법 (analytic hierarchy process: AHP)을 통해 이용자 중심의 스마트공원 조성 시 우선적으로 지향해야 할 가치 및 공원서비스가 무엇인지 그 상대적 중요도를 평가하는 것을 목 적으로 하였다.

\section{II. 이론 및 선행연구 고찰}

\section{1. 스마트공원 관련 선행연구고찰}

스마트 공원의 개념과 관련하여 Lee(2018)는 자연과 인간, 커뮤니티를 회복하고 증진할 수 있는 첨단 지능형 공원으로, Yoon(2015)은 IT기술을 통해 이용자 중심의 서비스를 제공하 여 도시공원의 기능을 강화할 수 있는 공원이라고 정의하였다. 최근 Lee et al.(2019)의 연구에서는 "디지털 - 환경 - 재료기술 등을 활용하여 시민들의 안전하고 쾌적한 공원 이용과 관리 운영의 효율 개선을 지원하여, 도시 및 지역사회의 사회 - 경제 및 환경적 지속가능성 확보에 기여하는 공원"으로 정의했다. Yoon(2015)은 이용자의 요구사항을 수집하기 위해 스마트파크 서비스요소를 도출하였으며, 이를 바탕으로 구축한 서비스 플 랫폼을 이용하여 구룡공원 등 실제 공원에 필요한 스마트파크 서비스를 제안하였다. Lee(2018)의 연구에서는 스마트도시에 대한 고찰을 통해 스마트공원의 개념을 정립하였으며, 국-내 외의 스마트도시와 스마트공원에 대한 전반적인 분석과 제도 고찰을 통해 개념을 정립하고, 일반인과 전문가의 가치 인지를 조사하여 제도개선 사항을 제시하였다.

공원시설물 관리에 스마트기술을 적용하는 방안에 대한 연
구로는 주로 스마트기기를 이용하여 전반적인 공원 관리 시스 템을 구축하는 연구가 많았다. 특히, Rho(2015)의 연구에서는 스마트폰앱과 웹페이지를 개발하고, 현장에서는 $\mathrm{QR}$ 코드와 $\mathrm{RFID}$ 를 이용하여 공원관리시스템을 구축하고, 실험을 통해 공 원 시설물 관리 분야의 스마트기술 적용 가능성을 확인하였다. 또한 Lee et al.(2012)의 연구에서는 스마트가로등 시스템을 도 시공원에 적용하는 시나리오 구성을 통해 스마트가로등의 경 제적 효과를 확인하였다. Park et al.(2018)의 연구에서는 화장 실에 IoT기술을 접목하여 이용자와 사용자가 모두 편리하며 안전한 화장실관리 시스템을 구축하고자 하였다. 조경수목 관 리를 위한 연구도 진행되었는데, Lee(2017)의 연구에서는 드론 과 환경 및 수목 감지센서 등을 이용하는 수목관리시스템을 구 축하고, 실증실험을 통해 데이터를 수집하는 연구를 진행하였 다. Rho(2018)는 범죄예방환경설계의 검토를 위해 가상현실공 간을 구축하여 다양한 환경에서의 설계 과정에 대한 검토가 가 능하다는 것을 입증하였으며, 증강현실기법을 이용하여 생태교 육 컨텐츠를 가상으로 구축하는 연구(Choi and Kim, 2013)가 진행되는 등 다양한 스마트기술 적용가능성이 시험되고 있다.

한편, 그동안의 U-City와 스마트도시 개발과정에서 지적된 문제점 또는 한계점은 스마트공원 조성에 있어 중요한 참고자 료가 된다. Yim et al.(2008)은 U-City 추진에 관한 관점을 기 술 주도의 관점과 서비스 주도의 관점을 분류하고, 기술관점이 아닌 도시의 기능 및 서비스 관점에서 도시의 진화를 설명할 필요가 있다고 주장하였다. Choi et al.(2019)은 또한 그간 스마 트도시가 기술적 측면만이 강조되고, 정주공간으로서의 도시의 기능과 의미가 간과되고 있음을 지적하였다. Lee(2018)는 스마 트도시 개발에 있어 지자체들이 각 지역이나 도시에 필요한 서 비스를 고민하고 개발하기보다는 사업자로부터 제공되는 기술 들을 인수하는 방식으로 진행됨에 따라 거의 모든 지자체가 도 시의 특성과 상관없이 동일한 서비스 솔루션을 가지는 획일화 되었다는 점을 지적하였다. Park and $\operatorname{Kim}(2019)$ 역시 도시와 지역이 가진 문화와 역사, 개성이 무시되고, 통합된 시스템 체 계 속으로 도시가 끼워 맞춰지고 있음을 비판하였다. 이러한 측면에서 스마트공원 개발에 있어서 첨단기술의 일방적인 수 용이 아닌, 공원 본질적 기능에 대한 고찰과 이용자의 요구에 기반한 서비스 관점에서의 접근이 필요함을 제시하고 있다.

\section{2. 도시공원의 기능 및 서비스}

도시공원의 본래의 기능과 서비스를 고찰하면, 도시공원은 산업화의 영향으로 발생된 다양한 도시문제를 해결하기 위해 조성되어 오늘날까지 오염된 도시의 공기를 정화하고, 도시민 들에게 자연과 접촉할 기회를 제공함으로써 도시민들의 정서 적 안정 및 신체적 건강을 유지하고, 삶의 질을 향상하는데 중 
요한 역할을 하고 있다(Sung and Seo, 2009). 최근에는 도시열 섬현상이나 초미세먼지현상 등의 여러 기후변화 문제를 해결 하는데 도움을 주고, 홍수나 지진, 태풍과 같은 자연재해나 재 난을 예방 - 저감시키며, 지진발생 시 대피할 수 있는 방재기능 의 역할이 커지고 있다(Kim, 2011). 도시공원은 주민의 참여를 유도하여 사회적인 접촉의 기회를 높일 수 있는 공간을 제공하 며, 노인이나 장애인, 또는 이주민과 같은 사회적 약자들에게도 우호적이며 더 다양한 주민참여를 제고하는 등 사회통합차원 에서도 중요한 서비스를 제공한다(Shim et al., 2010). 이러한 공원의 역할을 고려한 프로그램 구성을 통해 지역사회 주민들 은 지역사회에 대한 애착심이 고양됨으로 사회통합기능이 더 욱 촉진될 수 있다(Bae and $\mathrm{Kim}, 2013)$. 이러한 다양한 공원서 비스들이 스마트공원에서도 지속적으로 제공되고, 이용자의 요 구에 부합할 수 있도록 이용자 요구사항을 반영한 서비스 체계 관련 연구의 필요성도 제기된다(Yoon, 2015).

\section{III. 연구방법}

본 연구에서는 스마트공원이 지향해야 할 우선가치 및 목표, 그에 따른 공원서비스의 상대적인 중요도를 분석하는 것을 목 표로 하였으며, 이를 위해 다음과 같은 순서로 연구를 진행하 였다(Figure 1 참조). 첫째, 스마트공원 서비스 항목을 추출하 기 위하여 공원 기능 및 서비스에 대한 선행연구 및 문헌을 고 찰하였으며, 둘째, 스마트공원 조성 경험이 있는 IT전문가 및 조경분야 전문가를 대상으로 포커스그룹 인터뷰(focus group interview: $\mathrm{FGI}$ )를 실시하였다. 셋째, 문헌고찰과 $\mathrm{FGI}$ 를 통해

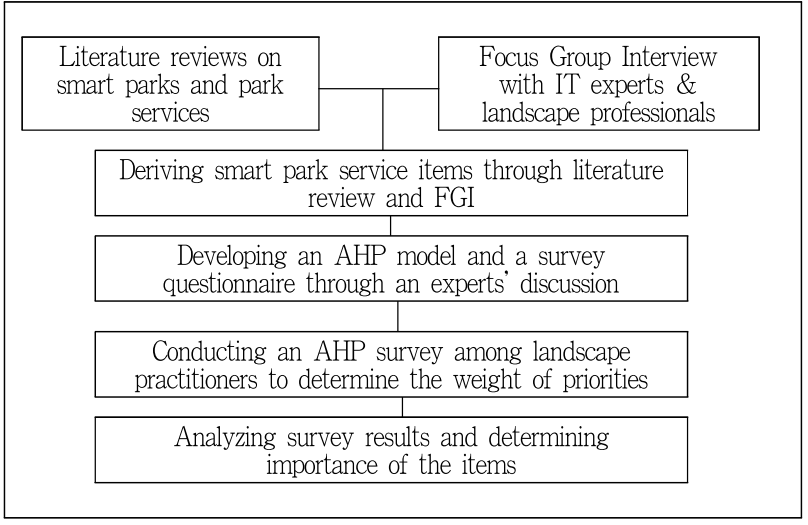

Figure 1. A research flowchart

도출된 항목을 종합하여 $\mathrm{AHP}$ 모델을 구축하고 설문지를 작성 하였다. 넷째, 스마트공원 서비스의 중요도를 산정하기 위해 조 경관련 전문가들을 대상으로 설문조사를 실시하였다.

\section{1. 스마트공원의 가치 및 서비스항목 추출}

스마트공원의 서비스 항목선정을 위하여 관련 문헌 및 선행 연구를 고찰하였는데, 공원의 본질적인 서비스 및 가치 연구, 공원서비스 유형분류 연구, 스마트공원 관련 연구, 스마트시티 서비스체계 관련 자료를 분석하였다. 수집된 자료를 토대로 각 자료들의 공원서비스와 관련된 키워드를 나열하고, 중복도를 체크하여 스마트공원과 관련성이 높은 서비스 항목을 도출하 였다. 문헌 및 선행연구에서 도출된 서비스 항목은 유사성을 고려하여 Table 1 과 같이 건강, 휴식, 놀이, 자연, 편안함, 기후

Table 1. Classification of park service items by literature reviews

\begin{tabular}{|c|c|c|c|c|c|c|c|c|c|c|c|c|c|c|c|}
\hline \multicolumn{2}{|c|}{ Theme / literature } & Health & $\begin{array}{c}\text { Relax- }^{-} \\
\text {ation }\end{array}$ & Play & Nature & Comfort & $\begin{array}{l}\text { Climate } \\
\text { change }\end{array}$ & Ecology & $\begin{array}{l}\text { Enviro- } \\
\text { nment } \\
\text { preser- } \\
\text { vation }\end{array}$ & Safety & $\begin{array}{c}\text { Social } \\
\text { integra } \\
\text {-tion }\end{array}$ & $\begin{array}{c}\text { Commu } \\
\text {-nity }\end{array}$ & $\begin{array}{l}\text { Edu- } \\
\text { cation }\end{array}$ & $\begin{array}{c}\text { Main- } \\
\text { tenance }\end{array}$ & $\begin{array}{c}\text { Park } \\
\text { opera- } \\
\text { tion }\end{array}$ \\
\hline \multirow{3}{*}{ Smart park } & Yoon (2015) & O & O & 0 & 0 & & & 0 & 0 & 0 & & 0 & 0 & 0 & \\
\hline & Lee(2018) & 0 & 0 & 0 & 0 & 0 & 0 & & & 0 & 0 & 0 & 0 & 0 & 0 \\
\hline & Loukaitou(2018) & 0 & & & 0 & & 0 & & 0 & 0 & 0 & 0 & & 0 & 0 \\
\hline \multirow{7}{*}{$\begin{array}{l}\text { Park value } \\
\& \text { services }\end{array}$} & $\operatorname{Park}(1996)$ & & & & 0 & & & & ○ & & & 0 & & & \\
\hline & Byun and Lee(2002) & 0 & & $\bigcirc$ & 0 & 0 & 0 & & & & & 0 & & & \\
\hline & Sung and Seo(2009) & 0 & 0 & 0 & 0 & & 0 & 0 & 0 & 0 & & 0 & 0 & & \\
\hline & Shim et al.(2010) & 0 & 0 & 0 & 0 & & & & 0 & & 0 & 0 & & 0 & \\
\hline & $\operatorname{Kim}(2011)$ & 0 & 0 & & $\mathrm{O}$ & & 0 & 0 & 0 & 0 & & 0 & & & \\
\hline & Bae and $\operatorname{Kim}(2013)$ & 0 & & O & & & 0 & 0 & 0 & & & 0 & 0 & & \\
\hline & CABE Space(2008) & 0 & $\bigcirc$ & O & $\mathrm{O}$ & 0 & 0 & 0 & 0 & 0 & & 0 & 0 & & \\
\hline \multirow{4}{*}{ Smart city } & Kim and Nam(2010) & 0 & & & & & 0 & & 0 & 0 & 0 & 0 & 0 & & \\
\hline & Kim and Jung(2019) & 0 & & O & O & & O & & 0 & 0 & & 0 & 0 & 0 & \\
\hline & Moon et al.(2017) & 0 & & & O & & 0 & & 0 & 0 & & 0 & 0 & 0 & 0 \\
\hline & $\mathrm{Ok}(2018)$ & 0 & & & & 0 & & & 0 & 0 & & & 0 & 0 & \\
\hline
\end{tabular}


변화대응, 생태, 환경보전, 안전, 사회통합, 지역사회·주민참 여, 교육, 시설물관리, 운영으로 분류하였다.

스마트공원은 개념정립 및 관련 정보가 많지 않은 상황이기 때문에 관련 전문가들의 의견을 구하는 전문가 심층인터뷰 (FGI) 방법을 이용하였다. FGI는 질적 연구 방법 중의 하나로 서, 주로 알려진 정보가 많지 않은 주제에 대한 연구초기에 사 용되며, 배경정보에 대한 빠른 획득, 새로운 아이디어 교환, 가 능성 진단 등의 장점이 있다(David and Prem, 2018). 정해진 주제에 대하여 자유롭게 토론하는 과정에서 참여자의 경험과 지식, 감정 등의 상호 작용을 통해 연구 문제에 대한 해결을 모 색한다. 본 연구에서는 2018년 10월, 2019년 6월 두 차례에 걸 쳐 전문가 10 명을 대상으로 FGI를 실시하였다. 스마트공원 시 범사업에 참여했던 IoT 전문가 2인을 포함하여, 공원설계 분야 2 인, 조경시공 및 관리 분야 3 인, 공원시설물 분야 1 인, 조경분 야 교수 2인 등 10-25년의 경력을 가진 전문가들로 구성되었다. FGI 그룹은 스마트공원의 개념과 가치, 주요 공원서비스, 개발 및 실천방향 등에 관하여 토의하였다. 기록 및 녹음된 인터뷰 내용은 종합하여 텍스트를 단위로 데이터를 구축하였으며, 구 축된 데이터는 공통된 주제를 범주별로 분류하고, 핵심적인 주 제를 도출하였다. 또한 구축된 데이터 내에서 공원서비스와 관 련이 있는 키워드의 빈도를 분석하고, 의미가 있다고 판단되는 구절과 문장을 찾아 각 키워드별 코드를 부여하여 체계적으로 범주화함으로써 스마트공원에 조성될 수 있는 공원서비스를 도출하였다. FGI에서는 스마트공원의 중요한 공원 서비스에 관한 키워드로 인간중심, 이용자 요구, 공간 쾌적성, 기후변화 대응과 같은 환경관련 서비스, 건강증진, 휴식처 제공과 같은 편의성 관련서비스, 지속가능한 운영 및 관리와 관련된 서비스, 교육과 문화 활동을 포함하는 사회통합서비스, 안전 관련서비 스 등이 항목으로 도출되었다.

\section{2. $\mathrm{AHP}$ 모델구성}

본 연구는 스마트공원의 공원 서비스에 대한 상대적 중요도 를 알아보기 위해 질적 - 양적 자료의 동시다발적인 분석이 가 능한 계층분석기법(AHP)을 이용하였다. 1971년 Saaty교수에 의해 개발된 $\mathrm{AHP}$ 기법은 평가 기준이 많고 복잡하거나 불확실 한 상황에서 대안을 설정하고, 논리적으로 평가하는 문제해결 형 의사결정 방법으로 논리적인 판단뿐 아니라, 주관이나 경험, 감정을 반영한 판단을 할 수 있다는 장점이 있다(Saaty, 2008). $\mathrm{AHP}$ 방법은 최종 목표를 설정하고, 평가기준과 대안을 설정 하여 계층구조를 만든 후, 최종 목표에 대하여 평가기준들 간 쌍대비교를 실행하여 그 중요도를 구하고, 각 평가기준에 대하 여 대안들 사이에 쌍대비교를 진행해 가중치를 구한다. 그 후, 최종목표에 대하여 각 대체안의 종합 평가치를 계산한다.
본 연구에서는 문헌고찰 및 $\mathrm{FGI}$ 를 통해 도출된 항목 내용을 종합하여 4 명의 조경 전문가의 논의를 거쳐 최종적으로 4 개의 공원가치 - 목표 상위항목과 15 개 공원서비스 하위항목으로 구 성된 $\mathrm{AHP}$ 모델을 구성하였다(Figure 2 참조). 건강-편안함 은 자연과의 접촉, 휴식, 운동·산책, 놀이 · 위락 등의 항목이 포함된 가치이며, 사회통합 가치는 지역사회 참여, 문화예술, 생태교육, 노인복지와 관련된 부문이다. 환경 - 안전의 가치는 미세먼지 저감, 폭염대비, 홍수예방, 범죄예방 등의 항목을 포 함하며, 마지막 관리 부문은 시설물 관리, 이용자 관리, 모니터 링 등 전반적인 공원운영과 관련된 항목들을 포함한다.

\section{3. 설문조사 및 분석}

설문조사에서는 $\mathrm{AHP}$ 설문문항과 함께 스마트공원에 대한 조경전문가들의 인식정도를 파악하기 위하여 스마트 공원에 대한 관심도, 인식, 필요성, 제약사항, 전망 등에 대한 의견을 묻는 질문을 포함하였다. 13명을 대상으로 한 예비조사를 통해 설문지 문항의 오류를 수정한 후, 2019년 6월에서 7월까지 이 메일이나 직접방문을 통해 배부하여 총 55 부를 회수하였다. 본 연구에서는 중심극한정리에 의해 정규분포를 가정할 수 있는 최소 표본 수 30명(Park and Kim, 2020)보다 많은 수의 표본 을 설정하였으나, 이 중 응답오류 3 부와 계층분석의 일관성지 수 0.2 이상의 설문지 14 부를 제외하고, 총 38 부를 최종 분석하 였다. 조사 대상자는 교육기관 종사자, 공공기관 종사자, 조경 설계 또는 시공 등의 조경실무 종사자를 대상으로 하였다 (Table 2 참조). 예비조사 결과, 스마트공원에 대한 관심 및 스 마트기술에 대한 인식정도가 젊은 층에서 더 높았고, 설문응답 에도 더 적극적인 것으로 파악되어 설문대상자에 있어 20-30대 의 비율을 높게 설정하였다. 수집된 설문 결과는 Expert Choice와 SPSS Statistics25를 이용하여 분석하였다.

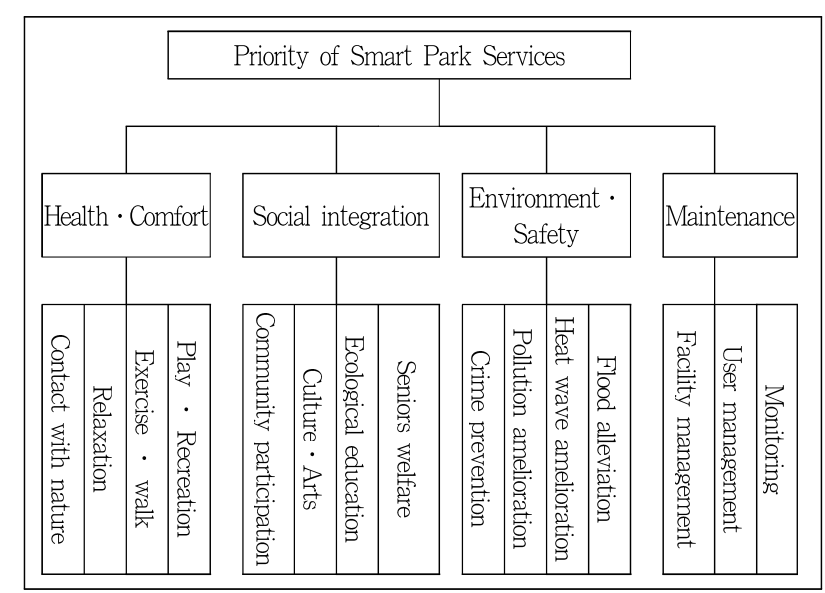

Figure 2. AHP model 
Table 2. Demographic characteristics

\begin{tabular}{c|l|c|c}
\hline \multicolumn{2}{c|}{ Characteristics } & Frequency & $\%$ \\
\hline \multirow{4}{*}{ Gender } & Female & 15 & 39.5 \\
\cline { 2 - 4 } & Male & 23 & 60.5 \\
\hline \multirow{4}{*}{ Profession } & $20-30$ s & 27 & 71.1 \\
\cline { 2 - 4 } & 40 s over & 11 & 28.9 \\
\cline { 2 - 4 } & Professor $\cdot$ lecturer & 6 & 15.8 \\
\cline { 2 - 4 } & Public employee & 22 & 57.9 \\
\cline { 2 - 4 } & Landscape practitioner & 6 & 15.8 \\
\hline \multirow{4}{*}{ Experience } & 5 years and less & 14 & 36.8 \\
\cline { 2 - 4 } & $5 \sim 10$ years & 11 & 28.9 \\
\cline { 2 - 4 } & $11 \sim 15$ years & 9 & 23.7 \\
\cline { 2 - 4 } & No responses & 4 & 10.5 \\
\hline & Total & 38 & 100 \\
\hline
\end{tabular}

\section{IV. 연구결과}

\section{1. 스마트공원에 대한 전문가 인식}

$\mathrm{AHP}$ 를 위한 설문 전, 응답자들의 스마트공원 또는 공원의 스마트기술 도입에 관한 인식정도, 필요도, 제약사항, 스마트기 술 관심정도, 스마트기술에 대한 숙련도에 관하여 질문하였으 며, 이에 대한 결과는 Table 3과 같다.

스마트공원에 대한 인식에 있어 응답자의 과반수 $(55.3 \%)$ 가 들어본 적이 있으나 잘 알지 못한다고 응답했으며, 들어본 적 이 없다는 응답자도 $18.4 \%$ 로 조사되었다. 평소 관심이 있었다 는 응답자(15.8\%)와 적극적으로 정보수집을 한 경험이 있는 응답자 $(10.5 \%)$ 는 상대적으로 적었다. 스마트공원 또는 공원의 스마트기술 도입 필요성에 대한 의견을 묻는 질문에 대하여, '필요하다'는 응답이 $47.4 \%$, '매우 필요하다'가 $13.2 \%$ 로 $60 \%$ 가 넘는 응답자가 스마트공원의 필요성을 인식하고 있었다. "보통 이다'는 응답은 $36.8 \%$, '필요 없다'라고 응답한 사람은 $2.5 \%$ 로 미미하였다. 스마트공원을 개발 및 조성하는 데 있어 응답자들 이 생각하는 제약 사항을 살펴보면, 재정적인 문제가 $50 \%$ 로 제일 높은 비율로 나타났고, 선행사례가 부족하다는 의견이 $23.7 \%$ 로 두번째로 높게 나타났다. 그외 IT기술에 대한 전문지 식 부족(18.4\%), 전문 인력의 부족(7.9\%) 등이 스마트공원 개 발에 제약사항으로 인식하는 것으로 조사되었다.

응답자들의 스마트 기술(IoT)이나 기기에 대한 관심 정도를 조사했을 때, '관심 있다' $(50 \%)$ 가 가장 많았고, '보통이다.' $36.8 \%$, '매우 관심 있다'와 '관심 없다' 응답은 각각 $5.3 \%$ 의 비 율로 조사되어 관심도는 높은 것으로 나타났다. 또한, 스마트
Table 3. Respondents' perception on smart park

\begin{tabular}{|c|c|c|c|}
\hline \multicolumn{2}{|r|}{ Responses } & Frequency & $\%$ \\
\hline \multirow{4}{*}{ Awareness } & Never heard of it & 7 & 18.4 \\
\hline & I am aware but don't know well & 21 & 55.3 \\
\hline & I have been interested & 6 & 15.8 \\
\hline & Have tried to get information & 4 & 10.5 \\
\hline \multirow{4}{*}{ Necessity } & Disagree & 1 & 2.6 \\
\hline & Neither agree nor disagree & 14 & 36.8 \\
\hline & Agree & 18 & 47.4 \\
\hline & Strongly agree & 5 & 13.2 \\
\hline \multirow{4}{*}{ Limitation } & Financial issue & 19 & 50 \\
\hline & Lack of IT knowledge & 7 & 18.4 \\
\hline & Lack of experts & 3 & 7.9 \\
\hline & Lack of success cases & 9 & 23.7 \\
\hline \multirow{5}{*}{$\begin{array}{l}\text { Interests in } \\
\text { smart } \\
\text { technology }\end{array}$} & Not at all interested & 1 & 2.6 \\
\hline & Not interested & 2 & 5.3 \\
\hline & Neutral & 14 & 36.8 \\
\hline & Interested & 19 & 50 \\
\hline & Very interested & 2 & 5.3 \\
\hline \multirow{4}{*}{$\begin{array}{l}\text { Proficiency } \\
\text { of smart } \\
\text { technology }\end{array}$} & Not proficient & 2 & 5.3 \\
\hline & Moderately proficient & 10 & 26.3 \\
\hline & Proficient & 18 & 47.4 \\
\hline & Very proficient & 8 & 21 \\
\hline \multicolumn{2}{|r|}{ Total } & 38 & 100 \\
\hline
\end{tabular}

기기에 대한 숙련도에 관한 질문에서는 '그렇다'가 $47.4 \%$, '매 우 그렇다'가 $21 \%$ 로 $68 \%$ 이상의 응답자가 스마트기기에 익숙 하다고 응답하였다. '보통이다' 응답자는 $26.3 \%$, '그렇지 않다' 의 응답비율은 $5.3 \%$ 로 조사되었다. 스마트공원 또는 공원의 스 마트기술 도입이 필요한 이유를 묻는 주관식 질문에 대하여, 공원의 안전성, 편의성을 높이고, 사회적 기능 등 공원의 기능 성 향상을 위해 필요하다는 응답이 가장 많았다. 또한, 4 차 산 업혁명 등 기술에 의해 급변하는 시대흐름에 맞추고, 관리 효 율성 제고와 폭염대비, 미세먼지 등 기후변화에 대응하기 위해 필요하다는 응답이 있었다. 그 밖에 노인인구의 증가, 범죄안전 등 인구변화 및 사회문제에 대한 대응하기 위해, 또한 시민들 의 요구에 부응하기 위해서 필요하다는 의견을 제시하였다.

\section{2. 스마트공원 서비스 항목에 관한 $\mathrm{AHP}$ 설문 결과}

$\mathrm{AHP}$ 분석 결과, 스마트공원이 우선적으로 추구해야 할 가 치는 건강 - 편안함(0.31), 환경 - 안전(0.298), 관리(0.242), 사 회통합(0.15) 순으로 나타났다(Table 4 참조). 부문별 항목의 중요도 순위를 비교해 보면, 건강 - 편안함 가치의 가중치 산정 결과는 자연접촉(0.305), 휴식(0.269), 운동·산책(0.269), 놀 이 · 위락(0.157) 순으로 나타났으며, 환경 - 안전 부문의 가중 
Table 4. Resulting criteria and item weights by AHP

\begin{tabular}{|c|c|c|c|c|c|}
\hline Value & Rank & $\begin{array}{c}\text { Value } \\
\text { weight }\end{array}$ & Item & Rank & $\begin{array}{c}\text { Item } \\
\text { weight }\end{array}$ \\
\hline \multirow{4}{*}{$\begin{array}{l}\text { Health } \\
\text { comfort }\end{array}$} & \multirow{4}{*}{1} & \multirow{4}{*}{0.31} & Contact with nature & 1 & 0.305 \\
\hline & & & Relaxation & 2 & 0.269 \\
\hline & & & Exercise $\cdot$ walk & 3 & 0.269 \\
\hline & & & Play $\cdot$ recreation & 4 & 0.157 \\
\hline \multirow{4}{*}{$\begin{array}{c}\text { Environment } \\
\cdot \text { safety }\end{array}$} & \multirow{4}{*}{2} & \multirow{4}{*}{0.298} & Crime prevention & 1 & 0.363 \\
\hline & & & Pollution amelioration & 2 & 0.245 \\
\hline & & & Heat wave amelioration & 3 & 0.223 \\
\hline & & & Flood alleviation & 4 & 0.168 \\
\hline \multirow{3}{*}{$\begin{array}{l}\text { Mainte- } \\
\text { nacne }\end{array}$} & \multirow{3}{*}{3} & \multirow{3}{*}{0.242} & Facility management & 1 & 0.368 \\
\hline & & & User management & 2 & 0.353 \\
\hline & & & Monitoring & 3 & 0.279 \\
\hline \multirow{4}{*}{$\begin{array}{c}\text { Social } \\
\text { integration }\end{array}$} & \multirow{4}{*}{4} & \multirow{4}{*}{0.15} & Community participation & 1 & 0.291 \\
\hline & & & Culture $\cdot$ arts & 2 & 0.268 \\
\hline & & & Ecological education & 3 & 0.245 \\
\hline & & & Seniors' welfare & 4 & 0.196 \\
\hline
\end{tabular}

치는 범죄예방(0.363), 미세먼지 저감(0.245), 폭염대비(0.223), 홍수예방 $(0.168)$ 순으로 나타났다. 사회통합 부문의 가중치 산 정결과는 주민참여(0.291), 문화·예술(0.268), 생태교육(0.245), 노인복지(0.196) 순이었으며, 관리 부문에서는 시설물관리 (0.368), 이용자관리(0.353), 모니터링(0.279) 순으로 가중치가 높게 나타났다.

한편, 15 개의 공원서비스 항목에 대하여 종합적으로 가중치 를 산정하여 상대적 중요도를 비교한 결과는 Figure 3과 같다. 스마트공원 서비스 중에서 가장 가중치가 높게 산정된 항목은 자연과의 접촉(0.103)이었으며, 범죄예방(0.099), 휴식(0.091), 운동 - 산책 $(0.091)$ 순으로 나타났다. 다수의 관리 및 환경 - 안 전 부문의 서비스 항목들이 전체 가중치 비교에서 중간 순위를 차지하였는데, 시설물관리(0.08), 이용자관리(0.077), 미세먼지 저감(0.067), 폭염대비(0.061), 모니터링(0.061) 등의 순으로 나 타났다. 마지막으로 놀이 - 위락(0.053), 주민참여(0.05), 문화 예술(0.046), 홍수예방(0.046), 생태교육(0.042), 노인복지 (0.034) 항목들은 상대적으로 낮은 순위로 나타났다.

\section{V. 결론 및 제언}

본 연구는 이용자 중심의 스마트공원 조성 시 지향해야 할 가치 - 목표와 우선적으로 제공되어야 할 공원서비스가 무엇인 지를 파악하기 위하여 전문가 심층인터뷰와 계층분석기법을 이용하여 설문을 진행하고 결과를 도출하였다. 연구결과를 통 해 도출된 결론을 요약하면 다음과 같다.

첫째, 전문가를 대상으로 실시한 계층분석 결과, 스마트공원

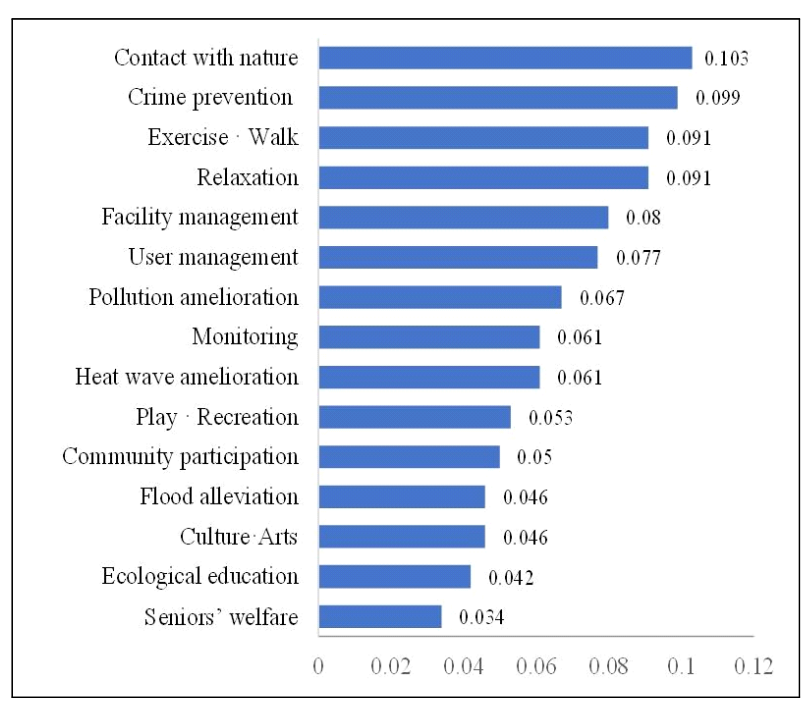

Figure 3. Priority of smart park service

의 중요한 공원서비스로서 자연과의 접촉이 가장 높게 나타났 으며, 휴식, 운동, 산책 등을 포함하는 건강 및 편안함 관련 항 목들이 중요도가 높은 것으로 조사되었다. 전문가들과의 인터 뷰에서도 스마트공원의 개발에 있어 우선적으로 추구해야 할 가치는 공원의 본질적인 기능을 향상 또는 강화라는 의견이 많 았다. 즉, 도시에서 결핍된 자연을 접하면서 휴식하고 건강을 위해 자연 속에서 운동과 산책을 즐길 수 있는 공원의 역할이 스마트공원이라는 새로운 공간으로 대체되는 것이 아니라, 기 존의 공원 기능을 더욱 원활히 하며, 이용자 활동에 편의성을 제공할 수 있는 방향으로 스마트기술이 적용되어야 한다는 것 이다. U-City 사업과 관련하여 “첨단기술 서비스는 보이지 않 고(invisible), 조용하며(calm), 편리(convenient)해야 한다'는 Lee(2008)의 주장이나, 공원은 다른 도시공간과 다른 '자연성' 이라는 특성을 가진 공간이므로 공원에 접목되는 기술은 기술 자체를 표출하기보다는 자연, 인간, 커뮤니티의 회복을 위한 방 향성을 가져야 한다는 Lee(2018)와의 주장과도 일치한다. 스마 트공원은 도시민들이 공원에서 기대하는 자연 속의 휴식과 치 유 활동이 유지되고 강화될 수 있도록 지원하는 스마트 콘텐츠 개발 및 관련 연구가 필요할 것이다.

둘째, 스마트공원의 중요한 서비스로 환경, 안전, 방재 관련 항목들의 순위가 상대적으로 높게 나타났다. 향후 기후변화로 인한 다양한 재해를 방지하고, 미세먼지나 폭염 등에 대비하는 공원의 재난재해 방지 및 안전성 강화를 위한 서비스 제공에 스마트 기술의 적극적인 활용이 더욱 필요할 것으로 전망된다. 한편, 현재 스마트공원에 적용된 스마트시설 대부분이 이렇게 센서 등을 통해 환경 및 범죄관련 정보를 인식하고 알림 등에 사용하는 초기단계 기술에 머무르고 있으며, 공원이나 해당 지 역의 특성이나 역사, 문화와 상관없이 적용되는 것은, 스마트도 시의 사례와 같이 개성없이 획일화되는 문제(Park and Kim, 
2019)를 초래할 수 있다. 또한 이러한 기술들은 도시공간 곳곳 에 적용되는 치안유지, 환경 정보제공 수준에 머물러 있는 한 계를 가지며, 도시공원에 특화된 스마트기술이라고 보기는 어 렵기 때문에, 환경 및 안전과 관련한 스마트기술이라 할지라도 공원 및 지역 특성, 이용자의 요구 등이 반영되고, 공원만의 특화된 기술 및 서비스가 제공되어야 할 것이다. 또한 환경감 지 단계에서 더 나아가 시뮬레이션을 통한 상황 예측 및 적합 한 행동의 제안하는 서비스, 문제를 선제적으로 해결하는 자동 화 서비스단계로의 모색이 필요하며(Lee, 2008), 환경보호와 자연보존을 위한 시민들의 적극적인 참여를 유도할 수 있는 스 마트기술 개발도 필요할 것으로 보인다.

셋째, $\mathrm{AHP}$ 가중치 산정에 있어 지역주민 참여나 노인복지, 문화예술, 교육 등과 관련된 사회통합 부문은 상대적으로 낮게 나타났으나, 전문가의 토론은 스마트공원이 지향해야 할 우선 가치로 논의되었다. 이는 사회통합 가치의 중요도가 낮다기보 다는, 그동안 익숙하게 접했었던 스마트 방범장치나 미세먼지 감지기 등의 스마트기술에 비해 사회통합 관련 기술에 대한 정 보가 상대적으로 부족한 면도 영향이 있을 것으로 판단된다. 시민들의 스마트기술 체감도 측면을 고려하였을 때, 방범이나 관리와 관련한 서비스는 시민들이 체감하는 서비스 효과가 상 대적으로 낮을 것으로 예측되었는데(Lee, 2008), 실제 대구시 스마트공원 이용자를 대상으로 한 설문조사에서 스마트공원에 대해 인식하고, 이를 체감한 이용자의 비율은 매우 낮았다(Lee et al., 2019). 이에 반해 사회통합 서비스는 스마트공원의 추진 계획 수립과 운영관리과정에 지역주민들의 참여를 활성화하고, 다양한 문화예술 활동을 통해 스마트공원에 대한 이해도를 제 고할 수 있을 것이다. 또한 지역특성을 반영하는 스마트공원 개발과 운영을 통해 이용자의 친밀감을 높이고, 스마트공원의 홍보교육을 강화함으로써 이용자들의 체감도는 높아질 것으로 전망된다(Kim and $\mathrm{Ha}, 2019)$.

결론적으로 스마트공원은 첨단기술을 활용하여 도시공원의 본질적인 기능과 서비스를 강화하고, 사회적 - 환경적 문제들에 대응함과 동시에 주민 참여를 통해 지역특성이 반영되고, 주민 들에 의해 지속될 수 있는 방안으로 계획되어야 할 것이다. 본 연구의 한계점으로는 스마트공원 관련 문헌자료가 부족하여 포괄적인 서비스 항목도출에 제약이 있었다. 또한 전문가 선정 에 있어 상대적으로 스마트기술에 익숙하고 관심이 있는 젊은 연령층과 공무원 및 공공기관 종사자의 응답비율이 높았으며, 다양한 분야의 많은 전문가들의 의견들이 반영되지 못했다는 점에서 결과의 일반화에 한계가 있다. 그러나 스마트공원에 대 한 체계적인 개념이 정립되지 않았고 관련 연구가 부족한 상황 에서, 스마트공원의 중요한 가치와 공원서비스에 대한 전문가 들의 의견을 정량적으로 분석하고 기초자료를 구축했다는 점 에서 본 연구의 의의가 있다. 이는 스마트 공원의 기초연구로
서, 향후 이용자 중심의 스마트공원 개발계획 및 조성방안에 대한 활발한 논의와 관련 연구들이 진행될 것으로 기대한다.

\section{References}

1. Bae, M. K. and Y. R. Kim(2013) Development of urban park supply altematives considering the equity evaluation of urban park service. The Korean Spatial Planning Review 77: 49-66.

2. Byun, B. S. and B. J. Lee(2012) Strategies for conserving green spaces for a pleasant urban environment. Research Report to Korea Environment Institute.

3. CABE Space(2008) Making the invisible visible - the real value of park assets. Report to Design Council.

4. Choi, B. M., E. T. Go., S. I. Lee, T. H. Kim, J. K. Lee, J. S. Lee, S. N. Kim, K. H. Cho, and H. J. Lee(2019) Smart urban planning in terms of urban space policy. Korea Planning Association 453: 4-17.

5. Choi, J. M. and U. Kim(2013) A study on the smart service of ecological education using technique of augmented reality for community board and smart phone. Journal of The Korea Institute of Spatial Design 8(1): 97-106.

6. Choi, J. H. and J. H. Suh(2019) Exploring the 4th industrial revolution technology from the landscape industry perspective. Landscape Journal 47(2): 59-75

7. David, W. S and N. S. Prem(2018) Focus Group Study Methodology 강종구 (역). 경영학, 학지사.

8. Jeong K. S., T. H. Moon and S. Y. Heo(2009) A study on u-city service classification and the service framework for the standardization of u-city service. Korea Planning Association. 44(3): 231-246.

9. Kim, Y. G., Y. M. Song, and S. K. Cho(2020) Design and management direction of smart park for smart green city. Landscape Journal 48(6) : 1-15.

10. Kim, B. J. and H. S. Ha(2019) Exploring the determinants of citizens' perceptions of smart city: Focusing on comparison of new and established cities in South Korea. Journal of the Korea Urban Management Association 32(3): 63-79.

11. Kim, J. K. and S. T. Nam(2010) Preference analysis for u-city services. Journal of the Korea Association of Information Systems 19(4): $51-63$

12. Kim, Y. W.(2011) Impacts of Urban Residents' Park Use Behavior on the Satisfaction with Park and Leisure Satisfaction. Ph. D. Dissertation. University of Sejong.

13. Kim, M. J and S. H. Jung(2019) Current trend of smart city service application in Korea. Journal of the Korea Contents Association 19(2) : 194-203

14. Kim, Y. K. (2017) "안 터지는 IoT-AR ․ㅗㄱㄱㄱ 터지는 스마트 공원", Daily Newspaper, October 10.

15. Kim, Y. M. and J. H. Koo(2019) Study on the developing of evaluation indicators for smart city from the perspective of digital social innovation. Journal of the Korea Contents Association 19(10): 511-521.

16. Lee, B. C.(2008) Beyond u-city chasm. SW Insight Policy Report, 29-49.

17. Lee, E. Y.(2018) A Study on the Strategies and Improvements of the Regulations for Smart City Parks. Ph. D. Dissertation. University of Hanyang.

18. Lee, H. S., B. W. Min, T. J. Yang, J. H. Eum, K. Kim, and J. Y. Lee (2019) A study on the concept and user perception of smart park-focused on the IoT see park users in Daegu City. Landscape Journal 47(5): 41-48. 
19. Lee, J. H.(2017) A Basic Study on Smart Tree Platform. Master Thesis. University of Hongik.

20. Lee, J. H., H. B. Cho and T. H. Kim(2012) A study on the profitable urban park model using smart street light system. Landscape Journal $40(4): 28-35$.

21. Loukaitou-Sideris, Jessup, K(2018) Smart Parks: A Toolkit. UCLA Luskin Center, USA.

22. MOLIT(Ministry of Land, Infrastructure and Transport)(2019) The 3rd Smart City Comprehensive Plan(2019 2023), MOLIT.

23. Moon, J. K., B. H. Jo, and B. M. Choi(2017). A basic study on service provision considering demand and satisfaction of smart city urban service. Journal of the Korea Contents Association: 269-270.

24. Ok, J. A. (2018) Developing New Smart City Services and Specialized District. Research Report to Kyonggi Development Institute.

25. Park, H. J. and H. S. Kim(2020). A basic study on the indicators development of regional safety of seismic disaster using AHP. Journal of the Korean Housing Association 31(6): 99-108.

26. Park, K. H. (2020) "ICT로 쾌적한 쉼터 조성... 스마트공원 전국 확산" Information and Communication Newspaper, November 2.

27. Park, M. H.(1996) Application of analytic hierarchy process to decide the priority of undeveloped neighborhood park. Landscape Journal 24(1): 42-54.

28. Park, N. R., J. M. Park, E. J. Bae, and K. S. Kong(2018) Develop- ment of lot-based smart toilet management system. Information Scientists and Engineers: 2217-2219.

29. Park, Y. J. and M. J. Kim(2019) A study on the development of residents' experience-oriented smart city service and local specialization plan. Urban Design 20(4) : 101-114.

30. Rho, S. M.(2018) A Study on Construction of Virtual Reality Space and the Measurement of Psychological Anxiety for the Application of the CPTED Simulation. Master Thesis. University of Seoul.

31. Rho, S. S.(2015) A Study on Efficient Management of Facilities in Parks Based on Smart Devices. Ph.D. Dissertation. University of Sungkyunkwan.

32. Saaty, T. L.(2008) Decision making with the analytic hierarchy process. International Journal of Services Sciences 1(1): 83-98.

33. Shim, J. Y., Y. I. Kim, and S. Y. Lee(2010) An evaluation of parks as public services. Landscape Journal 37(6): 19-27.

34. Sung, H. C., and J. Y. Seo(2009) User-Driven Urban Park Development Plan. Research Report to Kyonggi Development Institute.

35. Yim, C. S., N. S. Baek, and B. G. Kim(2008) A service-oriented city framework. Proceedings of the 2nd International Symposium on National Asset Management of Civil Infrastructure. pp.137-143.

36. Yoon, J. W.(2015) User-Centered Platform of Smart Park Service. Master Thesis. University of Hongik.

Received : 15 July 2021

Revised : 17 August 2021

Accepted : 17 August 2021

(1st) 